Max Weigel, Manfred Fischedick, Joachim Marzinkowski, Petra Winzer

\title{
Multicriteria Analysis of Primary Steelmaking Technologies
}

Originally published in:

Journal of Cleaner Production, vol. 112, part 1, 2016, 1064-1076 DOI: $10.1016 /$ j.jclepro.2015.07.132 
Max Weigel $a$,

Manfred Fischedick a

Joachim Marzinkowski b

Petra Winzer b

\section{Multicriteria Analysis of Primary Steellmaking Technologies}

a Wuppertal Institute for Climate, Environment and Energy, Germany

b University of Wuppertal, Faculty of Civil Engineering, Germany

* Corresponding author:

Max Weigel

Wuppertal Institute for Climate, Environment and Energy

Research Group Future Energy and Mobility Structures

Döppersberg 19

42103 Wuppertal

Germany

E-mail: weigel.max@gmail.com

Phone: +49 17620803750

This is the author's version of a work that was accepted for publication. Changes resulting from the publishing process, such as editing, corrections and structural formatting, may not be reflected in this document. Changes may have been made to this work since it was submitted for publication. A definitive version was subsequently published in the Journal cited above. 


\section{Contents}

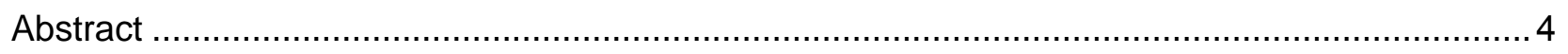

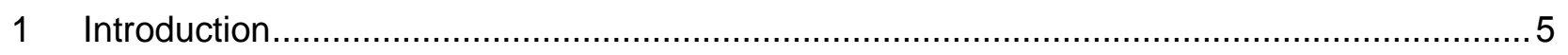

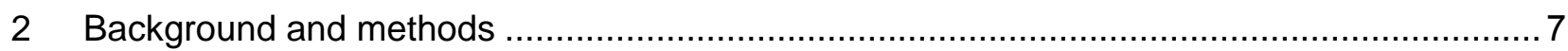

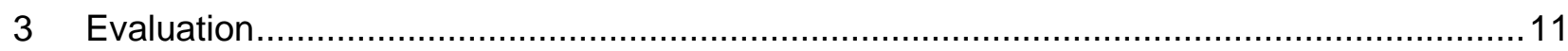

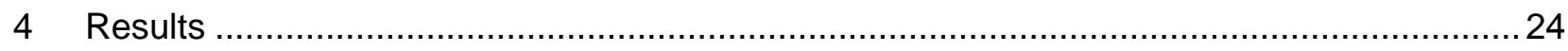

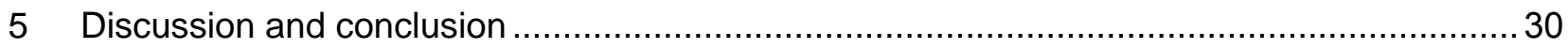

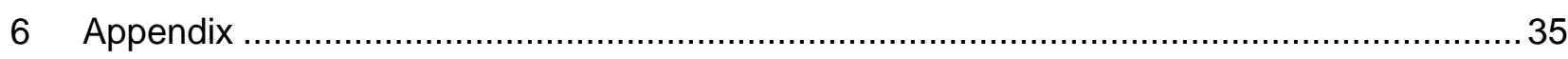




\section{Abstract}

The climate impact of the iron and steel industry can be mitigated through increased energy efficiency, emission efficiency, material efficiency, and product use efficiency resulting in reduced product demand. For achieving ambitious greenhouse gas (GHG) mitigation targets in this sector all measures could become necessary. The current paper focuses on one of those four key measures: emission efficiency via innovative primary steelmaking technologies. After analysing their techno-economical potential until 2100 in part A of this publication, the current research broadens the evaluation scope for the crucial year 2050, based on a Multicriteria-Analysis (MCA). 12 criteria from five different categories ("technology", "society and politics", "economy", "safety and vulnerability" and "ecology") are used to assess the same four future steelmaking technologies in a systematic and holistic way in Germany, as one possible location. The technologies in focus are the blast furnace route (BF-BOF), blast furnace with carbon capture and storage (BF-CCS), hydrogen direct reduction (H-DR), and iron ore electrolysis (EW). These four technologies were selected, as explained in part A of this paper, because they are the most commonly discussed technological options under discussion by policymakers and the iron and steel industry. The results of the current work should provide decision makers in industry and government with a long-term guidance on technological choices.

In 2050 the MCA shows significantly higher preference scores for the two innovative routes H-DR and EW compared to the blast furnace based routes. The main reasons being higher scores in the economical and environmental criteria. BF-CCS shows its greatest weakness in the social acceptance and the safety and vulnerability criteria. BF-BOF has the lowest economy and ecology score of all assessed routes, which is due to the projected high cost for carbon dioxide emission and increasing prices for fossil fuels. A first indicative trend assessment from today towards the MCA results in year 2050 shows that H-DR is the preferred option much earlier, starting from today on.

Three exemplary weighting distributions (representing the perspectives of the steel industry, environmental organisations and the government), used to simulate different stakeholder angle of view, don't have a strong influence on the overall evaluation of the steelmaking routes. The results remain very similar, with the highest scores for the innovative routes (H-DR and EW). This 
leads to the conclusion that EW and in particular H-DR can be identified as the preferred future steelmaking technology across different perspectives.

Specific innovation efforts and dedicated programs are necessary to minimize the time until marketability and to share the development burden. The similarity of the MCA results from different perspectives indicates a great opportunity to reach a political consensus and to work together towards a common future goal. Regarding the pressing time horizon a concentrated engagement for one (or few) technological choices would be recommended.

\section{Introduction}

Climate change is one of the crucial challenges for humanity. Since the pre-industrial era the concentration of greenhouse gases (GHG) in the atmosphere has risen steadily from below 300 ppm (1900) to a new record high of 400 ppm in May 2013 (Birol et al., 2013: 11). In order to maintain a chance to keep global warming below $2^{\circ} \mathrm{C}$, the maximum threshold is considered to be $450 \mathrm{ppm}$ and would be reached in 30 years at current emission levels (World Meteorological Organization, 2013: 2). Drastic climate change mitigation is necessary across the world to achieve this target. As suggested by the Intergovernmental Panel on Climate Change (IPCC) for developed countries the EU targets to reduce GHG emissions by $80-95 \%$ by 2050 (European Commission, 2011: 3).

The iron and steel industry, one of the most energy-intensive industries in Germany, is requested to contribute to the climate targets and to reduce GHG emission significantly by 2050 from 1990 level. Although no specific sector targets have been set so far, the EU Low Carbon Economy Road Map suggests that industry has to reduce GHG emissions by $80 \%$ by the middle of the century to achieve a total of $80 \%$ reduction by 2050 compared to 1990 level, while the transport sector has to contribute under proportionally and the energy sector has to achieve an almost complete decarbonisation (European Commission, 2011: 6). The European Union Emission Trading System (EU ETS) issues a decreasing number of carbon dioxide equivalent $\left(\mathrm{CO}_{2} \mathrm{e}\right)^{1}$

\footnotetext{
${ }^{1} \mathrm{CO}_{2} \mathrm{e}=$ measure that describes the global warming potential of any mixture of GHGs emissions in $\mathrm{CO}_{2}$ equivalents.
} 
emission allowances to the industry, asymmetrically increasing the cost for emission intensive technologies.

(Intergovernmental Panel for Climate Change (IPCC), 2014: 24-26) identified four main mitigation options for GHG emission reduction in the steel industry: Energy efficiency, emission efficiency, material efficiency, and product use efficiency resulting in reduced product demand. Even though steel product demand in some developed countries might peak within the current century, the world steel demand is considered to rise, following current projections (Pauliuk et al., 2013: D). A shift towards the secondary production route through recycling has a great impact on $\mathrm{CO}_{2} \mathrm{e}$ emission. Even though higher shares may be possible in long-term, due to embedded material less than $50 \%$ of the steel demand can be covered by the secondary route by 2050 (Morfeldt et al., 2014: 1; Wörtler et al., 2013). Additionally, high labour costs inhibit more extensive recycling (Intergovernmental Panel for Climate Change (IPCC), 2014: 25). Due to continuous optimization the industry is already approaching the theoretical minimum of $1371 \mathrm{~kg}$ $\mathrm{CO}_{2} \mathrm{e} / \mathrm{t} \mathrm{CS}$ (Kirschen et al., 2011: 6148) and little additional energy efficiency potential still remains in the core production processes. The current research hence focuses on emission efficiency through innovative primary steelmaking technologies.

The most common conventional primary production route is based on the blast furnace (BF) in combination with the basic oxygen furnace (BOF), which accounts for over $70 \%$ of the worldwide steel production (World Steel Association, 2014: 10).

In part A of this paper (Fischedick et al., 2014) the following innovative primary steelmaking technologies, which are most commonly discussed as future options in industry and politics, have been assessed in comparison to the BF-BOF route as reference:

- Blast furnace with basic oxygen furnace equipped with $\mathrm{CCS}^{2}$ (BF-CCS)

- Hydrogen Direct Reduction (H-DR)

- Electrowinning (EW)

Techno-economical models have been developed and were evaluated, considering different scenarios of the energy transformation in Germany. The results in part A (Fischedick et al., 2014)

\footnotetext{
${ }^{2}$ CCS $=$ Carbon Capture and Storage
} 
were clearly indicating, within the set of the analysed technologies that $\mathrm{H}$-DR could become the economically preferable option past 2040 . However, the need to include further criteria to the assessment was identified. The current paper aims to broaden the above mentioned assessment of primary steelmaking technologies in Germany for the focus year 2050, using a multicriteria analysis (MCA). The research question to be answered is: Which innovative primary steelmaking technology has the highest preference across different criteria in 2050 ?

The focus year 2050 was selected since the German government committed to reduce carbon emissions by 80\% (compared to 1990 levels) until 2050 (BMU, 2010). Hence the energy transition will have to be almost completed and the impact on the industrial landscape should be visible even in industries with long investment cycles like the steel industry. The method selected, the multicriteria analysis allows combining a variety of different criteria and stakeholder perspectives in one integral assessment process. Each criterion is carefully evaluated using literature information or simulated results from the techno-economic model mentioned above. Besides an equal reflection of each criterion, the criteria can be weighted by specific weighting factors (Zopounidis and Pardalos, 2010). In the current research three exemplary stakeholder perspectives are simulated with different sets of weighting factors (i.e., steel industry, environmental organisation, government). Thereby the selected steelmaking routes can be compared from different viewpoints.

\section{Background and methods}

After introducing the research question in the past section, this section aims to set the methodical background for the analysis. The method requirements are stated (see section 2.1) and translated into the specifications of the selected method (see section 2.2).

\subsection{Method requirement}

After a quantitative techno-economic assessment in part A (Fischedick et al., 2014), which is focused on solely technical and economic parameters, a consecutive evaluation for the focus year 2050 is conducted to broaden the assessment scope, aiming for a more holistic assessment of future technologies. Hence, various criteria from the categories "technology", "society and 
politics", "economy", "safety and vulnerability" and "ecology" are to be included into the assessment. Some of the criteria are quantitative, other are qualitative but should be equally considered in the assessment result. Furthermore, the evaluation method needs to meet the following requirements amongst others:

- Handle complex and multidimensional problems

- Include multi-stakeholder evaluation perspectives

- Reflect real-world problems with incomplete or imprecise data

- Consider subjectivity of involved stakeholders

\subsection{Method specification}

As discussed in (Mateo, José Ramón San Cristóbal, 2012) and (Zopounidis and Pardalos, 2010: 6 ), a suitable method for the above mentioned requirement is the multi criteria analysis (MCA), a popular method from the operations research discipline especially for complex decisions in renewable energy systems (Wang et al., 2009). The MCA is commonly used to prepare and support highly complex decision-making processes by considering a variety of conflicting criteria (Wuppertal Institute for Climate, Environment, and Energy (WI), 2012).

A MCA typically starts with the explicit definition of alternatives which are evaluated and compared with each other to identify the best solution for a given problem (Abu Taha and Daim, 2013: 3). The alternatives in the current research are BF-BOF, BF-CCS, H-DR, and EW. In a second step, criteria that reflect the relevant assessment dimensions (categories) and, in practice, allow a differentiation between the alternatives regarding the research question, are identified. The evaluation of the criteria for all alternatives creates a matrix which summarises the differences between the alternatives. Summing up the assessments for each criteria leads to a result regarding the preference among the considered alternatives (Department of Communities and Local Government, 2009: 49-71). Using certain weighting factors (see section 3.2), in addition, can help to reflect specific stakeholder perspectives and preferences. In contrast to optimization methods, in MCA there is no single optimal solution, but rather one or even several best fits. The consideration of different perspectives plays an important role and facilitates the identification of robust results.

\section{Criteria selection}


To receive valid results in an MCA, the criteria have to be carefully selected along the following quality requirements (Wuppertal Institute for Climate, Environment, and Energy (WI), 2012), (Department of Communities and Local Governement, 2009: 32-39):

- The criteria have to cover all relevant dimensions for decision-making

- Each criteria has to be relevant for evaluating the alternatives

- The criteria have to be represented by a parameter that can be used to evaluate them in practice

- Redundancy within the set of criteria have to be minimized

- The criteria have to be clearly categorized

Starting with the three pillars of sustainability (social, economic and environmental) ${ }^{3}$ a technological and a safety category were added, which were considered important for the assessment of steelmaking technologies. Based on the criteria selection in (Wuppertal Institute for Climate, Environment, and Energy (WI), 2012) and (Zeiss and Valentin, 2011) a long list of criteria was defined in team discussions by the authors. Through grouping and questioning redundancy and viability of each criterion in expert discussions, the number was reduced to 12 main criteria in the following five categories: technology, society \& politics, economy, safety \& vulnerability, and ecology. Each category reflects a sub-objective to the single main objective of the MCA process whereas each criterion reflects individual measurable parameters relative to the issue at hand (Franco and Montibeller, 2009: 34). Even though a certain criterion might fit in several categories, each criterion is only used once, avoiding double weighting of certain aspects. The criterion "resource dependency"; for example, could fit in categories "economy", "ecology" or as in the present criteria catalogue in the category "safety and vulnerability". Table 2-1 shows the criteria used for the MCA.

\footnotetext{
${ }^{3}$ International Organization for Standardization (ISO) (2013: 14)
} 


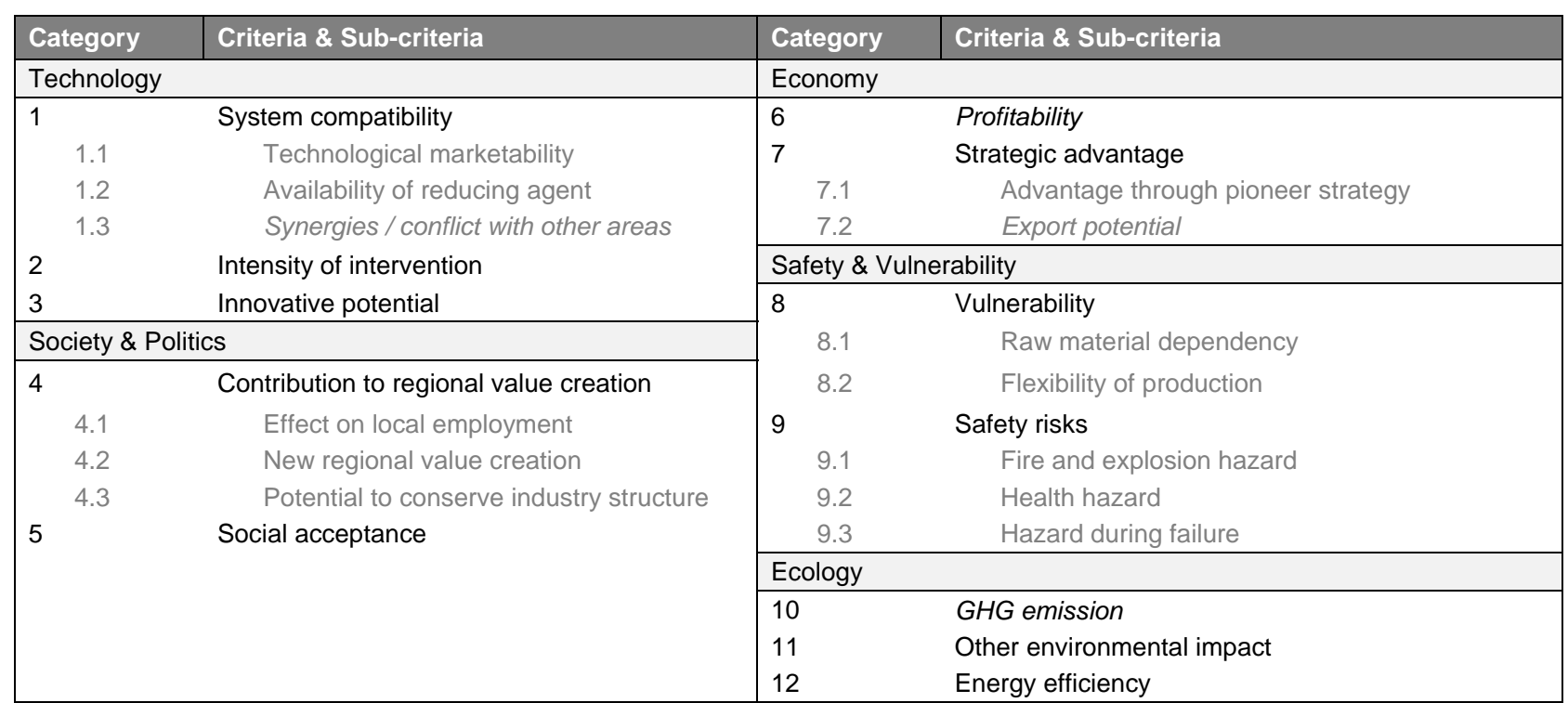

Table 2-1: Criteria catalogue for muti-criteria analysis (sub-criteria in grey; strongly time-dependent criteria in italic)

\section{Evaluation method}

Each of the four alternatives is scored on a ranking scale from 1 to 4 , depending on the relative rank regarding a certain criterion. Score 4 for the most suitable alternative and score 1 for the least suitable alternative. In case two alternatives have the same rank, the lower rank is used for both and the higher rank is skipped (e.g., if two alternatives are scored with rank 3, rank 4 is skipped).

The rank is based on a certain quantitative or qualitative parameter that is chosen to represent the criterion. The scoring of each criterion is discussed in detail in section 3.1 .

\section{Weighting method}

For the principal MCA the criteria are weighted equally. Each of the five categories is weighted with $20 \%$. Within the categories the criteria on the same hierarchy level receive the same weighting factor. In order to assess the effect individual weighting would have on the analysis result, three exemplary perspectives from the steel industry, an environmental organisation and the state government are simulated with individual sets of weighting factors. The analysis results based on these different sets of weighting factors are presented in section 4.2 .

\section{Timely trend indication}


As described above, the full MCA analysis is conducted for focus year 2050. Additionally an indicative trend of the MCA results from the base year 2010 until 2050 is included to provide a first idea of the timely evolution. This trend analysis is based on the timely evolution of four selected criteria with the strongest time-dependence (i.e. synergies \& conflicts with other areas, profitability, export potential, GHG emissions). All other criteria are assumed to be constant.

\section{Evaluation}

After the method has been specified the current section focuses on the evaluation of the four alternatives. First, ranking scores are derived along each criterion (see section 3.1). Then, different sets of weighting factors are chosen (see section 3.2) to derive the evaluation of each alternative.

\subsection{Scoring}

As described in (Wuppertal Institute for Climate, Environment, and Energy (WI), 2012), the evaluation of the four alternatives based on the criteria is done primarily with literature research and from results of the numerical model from part A (Fischedick et al., 2014). For the criteria that refer to a time dependent property, the values from the moderate scenario in year 2050 are used when climate targets are expected to be met. For some criteria, judgement from expert discussions is included into the scoring (e.g., public acceptance, innovation potential, etc.). Wherever applicable, the expert input is clearly cited in the text. In the following, the reasoning for the scoring of each criterion, based on the considered parameters, is presented systematically for each criteria category.

\subsubsection{Technology}

\section{Technological marketability (1.1)}

The main question is when the four options achieve economic maturity, i.e., are ready to be implemented in industrial scale?

The quantitative parameter for the ranking is the year of potential market entry. Obviously, the incumbent route BF-BOF with rank 1 receives score 4. According to (EUROFER, 2013: 42) BFCCS will be marketable by 2020 (score 2). H-DR is already considered to be marketable in areas 
with cheap natural gas supply (e.g. Circored plant in Trinidad) ${ }^{4}$ (score 3) and EW by 2040 (score 1).

Availability of reducing agent (1.2)

Is there a secure supply of the reducing agent for the alternatives on a short- and long-term basis?

Chosen parameters for this criterion are the compliance with the hourly demand and the compliance with the yearly capacity considering short-, middle- and long-term perspective. BFBOF as incumbent route has all value chain steps harmonized and can guarantee availability of coke as reducing agents at all times. The only risk might be a scarcity of high quality coking coal in long-term perspective (score 3). The situation for BF-CCS is almost identical. The reduced coke demand decreases the dependency on coking coal and therefore secures availability even more (rank 4). Large amounts of $\mathrm{H}_{2}$ are necessary as reducing agent for H-DR. Currently electrolysers with a capacity of approximately $1000 \mathrm{MW}_{\mathrm{el}}$ that would be necessary for a $2 \mathrm{Mt} /$ year H-DR steel plant are not available. In 2050, it is not sure whether hourly or annual availability of hydrogen can be secured (score 1). The necessary electricity to produce the annual capacity of $2 \mathrm{Mt}$ crude steel per year is already available today. It is preferable that the additional electricity demand would be covered by renewable sources. While the share of renewable energy in the electricity mix is still to grow, general availability of electricity can be secured already today and will most likely be in 2050 (score 2).

Synergies or conflicts with other areas (1.3)

Are there synergies or conflicts with developments in other sectors in 2050 (e.g., synergies through $\mathrm{H}_{2}$ application in transportation or energy generation, conflicts with CCS storage and competing use of underground storage)? The parameters in focus are the number and intensities of synergies on one hand and the number of conflicts on the other hand. BF-BOF is established as the predominant route; therefore, no major conflicts with other sectors are perceived. In contrary, many synergies exist and will potentially exist in 2050 with the energy and cement industry which use process waste like blast furnace slag and process gases (score 3). For BF-

\footnotetext{
${ }^{4}$ Nuber et al. (2006)
} 
CCS, the recycling of process gases and slag is significantly reduced through the CCS technology (TGR). High investment cost for $\mathrm{a} \mathrm{CO}_{2}$ infrastructure or missing public acceptance could impede investments in the necessary structures. Competing use of underground storage sites in 2050 could affect the implementation of needed energy storage capacities (score 1). No major conflicts are expected for H-DR. High infrastructure investment cost could inhibit investment into this alternative energy carrier. In contrast, as different energy scenarios highlight the general importance of $\mathrm{H}_{2}$ for the future energy system, many synergies are expected that are related to a wide application of hydrogen usage across different sectors in 2050 (like energy storage, transport, industrial applications, and grid and system stabilization) (Balat, 2008) (score 4). No synergies are expected for EW, but also no major conflicts with other sectors. Without a high share of renewable energy sources this alternative could conflict with climate targets due to the increased electricity demand (score 1 ).

This criterion is selected as one of the most time-dependent criteria and therefore further assessed regarding the time trend from 2010 until 2050. The trend of the MCA ranking can be found in the Appendix, section 6. In general the conflicts of the four technologies remain over time (e.g. new storage locations for BF-CCS, increased electricity demand for EW). The synergies of $\mathrm{H}-\mathrm{DR}$ increase from almost no synergies currently to manifold synergies in a hydrogen based energy system in 2050 (H-DR with score 1 in 2010 until score 4 in 2050). For BF-BOF the synergies with other sectors are strongest in 2010 and are becoming slightly less relevant towards 2050 with a largely renewable based energy system (score 4 in 2010 until score 3 in 2050).

\section{Intensity of intervention (2)}

How severe are the changes through the implementation of the alternatives for the iron and steel industry?

Representative parameters are depth and amplitude of changes that each technology can cause to processes, value steps, know how, structure and competition of the iron and steel industry. BF-BOF with no changes and hence no disruptive implementation has the first rank (score 4). $B F-C C S$, which is in general based on the conventional route, requests changes regarding the carbon sequestration, transportation, and storage. These changes are without any doubt significant, but focus "only" on the end of the pipe as the production step is still based on the 
conventional route. Overall and in comparison to other processes this results in the second rank (score 3). Since H-DR is based on the direct reduction technology, which is already in use, the changes are not very severe. In case of Germany with only one direct reduction plant in operation, severe changes would be necessary for almost all production sites (score 2). For EW severe changes would be necessary in all steps of the value chain. Implementing an entirely new production process not only requires additional know how, but leads to fundamental changes in supplier relations and competition (score 1).

Innovative potential (3)

How high is the future improvement potential of the alternatives within the investigation period? The parameter that describes this criterion is the development potential of each alternative from a long-term perspective. As described in section 1, the potential for further innovation is very small for the BF-BOF route (score 1). BF-CCS has a few areas for innovation related to development in $\mathrm{CO}_{2}$ transportation and especially $\mathrm{CO}_{2}$ capture and storage (score 2). $\mathrm{H}-\mathrm{DR}$ is still a young technology with many areas of improvement related to hydrogen production, storage and synergies. Also the hydrogen based direct reduction is expected to be further improved to reduce sticking of particles and have higher capacities and process efficiency (score 3). The youngest alternative, the EW route, is still in laboratory research stage, but has great innovation potential to become the most energy efficient, carbon free, steel production alternative, if the development is continued (Lavelaine and Allanore, 2008), (Yuan and Haarberg, 2008) (score 4).

\subsubsection{Society and politics}

\section{Effect on local employment (4.1)}

Is new employment created through the alternatives?

The representative parameter is the effect on the local employment situation through the relative labour intensity per tonne of crude steel. With the incumbent route BF-BOF no negative nor positive effects are expected on the local employment situation. The labour intensity remains unchanged at 0.5 man-hours / t crude steel (ECORYS SCS Group, 2008: 62) (score 1). The BFCCS alternative might create some new jobs in areas related to carbon capture and storage. The effect is considered to be small because most of the new process steps are fully automated (score 2). For the H-DR alternative, due to smaller production units, the labour intensity is expected to increase by about $40 \%$, which has a significant effect on local employment (Expert 
from steel industry, 2014). In addition, the production and storage of the reducing agent creates a few new jobs (score 4). The H-DR plant might not be at the same site of the conventional steel plant. Hence, the local employment effect might be in a different area. Also for the EW alternative a $40 \%$ staff increase is expected. Since no further process steps are required for the production of the reducing agent, this alternative is expected to create slightly less local employment than $\mathrm{H}$ DR (score 3).

\section{New regional value creation (4.2)}

Are new value creation steps diverted to the area of steel production?

The parameter is the number of the value steps diverted to the region of steel production at the time of market entry. For the BF-BOF alternative no new value steps are diverted but existing steps remain (score 2). For BF-CCS existing value steps remain and the carbon sequestration is added as a new value step. The carbon storage though will not affect the area of steel production because, given the current distribution of steel production sites in Germany, the storage site for the $\mathrm{CO}_{2}$ will most likely be some hundred kilometres away (score 3). Both, $\mathrm{H}$-DR and EW bring a new iron ore reduction technology to the steel plant. H-DR in addition, also diverts process steps related to hydrogen production and storage to the area of steel production, which will most likely be done locally to simplify storage (score 4). EW brings the new value step iron ore electrolysis to the area of steel production but reduces all former value steps (score 1).

\section{Potential to conserve industry structure (4.3)}

How do the alternatives influence industry structure closely related to the steel industry (based on Zeiss and Valentin, 2011: 95)? The parameter is the type of influence through the different alternatives on industry structures outside the steel industry (e.g. cement, construction, automotive, manufacturing, etc.) on the technology has entered the market.

In case of the BF-BOF alternative, the existing industry structures that are strongly related to the steel industry (i.e. cement industry, automotive, construction, and manufacturing) would be preserved in short-term, but not in long term due to the decreasing profitability of this alternative (score 1). Also for the BF-CCS, all existing industry structures currently in place would be preserved because this alternative is based on the BF-BOF route. In addition, the chances for a long-term profitable operation are slightly higher than for BF-BOF with a beneficial influence on 
the related industry structures (score 2). In case of H-DR, with a shift towards high quality steel, the positive influence on structures in automotive and manufacturing industries remain whereas structures based on low priced low quality steel, like construction industry would lose their current benefits. The reducing agent hydrogen might cause manifold positive effects on all hydrogen related industry structures in long-term, contributing to the future of the industrial site Germany (score 4). EW with a similar shift to high quality steel supports the industry structures that rely on high quality steel products. No additional positive influences similar to hydrogen in the case of EW (score 3).

\section{Social acceptance (5)}

How high is the acceptance within the public towards the alternatives?

The parameter is the perceived acceptance of the alternatives within the public today. A time dependency is possible for this criterion, but due to the erratic character a trend prediction seemed unrealistic. Expert judgement and literature sources were included to grasp the scoring of this criterion. The discussions with experts which cannot be considered representative and the author's judgement indicate that the perceived acceptance in the public is highest for the incumbent BF-BOF alternative (score 4). Due to controversial political discussion about CCS and numerous already existing citizens' initiatives against CCS the BF-CCS alternative is perceived to have the lowest public acceptance in Germany (score 1) (Oei et al., 2011). For hydrogen technologies the general public acceptance is very high (Yetano Roche et al., 2010: 5303), if safety standards are ensured. Local acceptance in the proximity of the production site is expected to be only medium due to safety concerns by residents regarding hydrogen storage (score 2). The popular green image creates an equally high social acceptance for the less known EW alternative. No safety concerns are expected for this alternative (score 3).

\subsubsection{Economy}

Profitability (6)

How profitable are the alternatives?

The parameter chosen to represent the profitability is the net present value (NPV) as a main financial indicator for investment decisions. The NPV of each alternative is calculated in the 
techno-economic model in part A (Fischedick et al., 2014: 571) ${ }^{5}$. In the moderate scenario in 2050, the BF-BOF alternative has the lowest NPV due to high cost for fossil fuels and $\mathrm{CO}_{2}$ emission (score 1). The BF-CCS with less $\mathrm{CO}_{2}$ emission and a reduction in coking coal consumption has a higher NPV (score 2). The highest NPV in 2050 is simulated for the H-DR alternative due to the use of cheap excess electricity at times of oversupply (score 4). EW has a slightly lower NPV because, without a buffer storage, the average electricity costs are higher (score 3).

This criterion also has a strong time-dependency. The NPV trend calculated from $2010-2050$ is shown in the appendix, section 6. BF-BOF starts out to be the most profitable option in the base year (score 4 in 2010) but then gradually loses profitability due to increasing fossil fuel prices and carbon taxes (score 1 in 2050). After market entry in 2020 BF-CCS starts out with a profitability of score 3, increases relative to the other alternatives in 2030 and 2040 (score 4) but then loses to the innovative technologies in 2050 (score 2). H-DR starts out with a low profitability due to high hydrogen prices in 2010 (score 2) but then gradually improves to reach the highest relative profitability in 2050 (score 4). EW is expected to have a low profitability at the time of market entry in 2040 (score 1) but is expected to improve rapidly in a largely electricity based energy system of the future (score 3 in 2050). The discrete NPV time development can be found in part A of this paper.

\section{Advantage through pioneer strategy (7.1)}

How high is the 'first-mover advantage' for the pioneer operating one of the alternatives (technology leadership) and what can be expected during the market deployment phase (e.g., experience curve, scale effect)?

The parameter measuring this criterion is the estimated degree of the advantage through early implementation of the alternatives.

The incumbent BF-BOF alternative only has the small area of incremental improvements where a first mover advantage is still possible (i.e., top gas recycling, direct injection of coal substitutes, improved heat recovery, etc.) (score 2). CCS is no new technology; therefore the advantage

\footnotetext{
${ }^{5}$ Simulation values from Fischedick et al. (2014) bare uncertainties discussed in the original paper and in brief in the limitations in chapter 5 .
} 
regarding a technology is not very high. On the other hand the great uncertainties regarding $\mathrm{CO}_{2}$ storage sites expose an increased risk on a first mover using the BF-CCS alternative, which is counterbalancing any advantage. For the BF-CCS alternative there is rather a 'first-mover disadvantage' expected (Expert from steel industry, 2014). (score 1). H-DR and EW as innovative technologies are expected to bring high 'first-mover advantages'. With cross-sector appliance of hydrogen technologies the 'first-mover advantages', including hydrogen technology leadership and learning effects, might be slightly higher (score 4) than for EW which is mainly applicable to metal production industries (score 3).

Long-term export potential of the steel product (7.2)

How high is the global demand for steel products from each of the production routes considering future carbon markets? The parameter is the relative export potential for steel from each alternative in 2050, when worldwide significant carbon prices might be likely. High international competitiveness leads to increased profitability and value creation in Germany. Changes in global steel demand or supply are negligible for this ranking because the ranking order is not affected. The BF-BOF alternative is not expected to have a high export potential towards 2050 because steel with a high $\mathrm{CO}_{2}$ footprint gets less popular on the world market and increasing production cost could cause uncompetitive prices (score 1). The BF-CCS alternative produces steel with a slightly smaller $\mathrm{CO}_{2}$ footprint and could remain profitable in the German market slightly past 2050 , leading to slightly better export potential than for BF-BOF (score 2). Both, $\mathrm{H}$ DR and EW alternatives are expected to have a high export potential because 'green' high quality steel will have high demand. Steel with low carbon content will be increasingly used for special high-quality steel products. Both routes could remain profitable and competitive even in a challenging market situation in Germany past 2050 (score 3).

The export potential was also selected as one of the criteria with the strongest time dependency. For BF-BOF the trend is expected to be most extreme. In 2010 and 2020 this is the alternative with the largest export potential as the predominant German steelmaking technology (score 4). Towards 2050 in the scenario with worldwide carbon policies this alternative is expected to have the lowest export potential (score 1). BF-CCS is expected to have a decent export potential (score 3) until the demand for carbon free technologies really picks past 2040 (score 2). Low carbon steel from the H-DR alternative is not expected to have a big demand in 2010 (score 1) 
but due to worldwide carbon awareness and policies is expected to have the highest demand together with EW in 2050 (score 3). EW starts with a decent demand after market entry in 2040 with score 3.

\subsubsection{Security and vulnerability}

Raw material dependency (8.1)

How high is the dependency on raw materials?

The parameter used for this criterion is the raw material cost share of the operating expenses (OPEX) based on the techno-economic model from (Fischedick et al., 2014: 569-570). With a raw-material cost share of 78\%, the BF-BOF and the BF-CCS alternatives have the highest dependency on raw materials (score 1). The H-DR alternative only has 60\% OPEX that are related on raw material prices (score 4). The EW alternative with the lowest raw material demand of all alternatives still has a slightly higher raw material cost share of $63 \%$ because of the expensive sodium hydroxide for the alkaline electrolyte (score 3).

\section{Flexibility of production (8.2)}

How flexible can the production output adopt to timely changing demand?

The parameters in focus are the delay for shutdowns and the scalability of the technology (i.e. flexibility to be operated in small decentralized units or large central plants). In addition to the author's judgment, expert knowledge is considered (Expert from steel industry, 2014). The BFBOF alternative, and especially the blast furnace is used in continuous operation because shutdown times are very long (Remus et al., 2013: 521). The blast furnace only achieves acceptable process efficiency if operated in large units (2-5 Mt / a) and hence there is hardly any flexibility regarding scalability. The only variation possible is a wide spectrum of steel types. Therefore, changing demand in one specific steel type could be compensated in a switch to a different type (score 2). For BF-CCS, the shut-down is even longer due to the top gas recycling and the $\mathrm{CO}_{2}$ sequestration aggregate (score 1); whereas direct reduction process of the H-DR alternative can be stopped and started quite easily. In addition, the smaller plant capacity (Ranzani da Costa, A. et al., 2013: 28) leads to a high scalability of production capacity (score 4). The chemical electrolysis process cannot be shutdown easily. The flexibility is still higher than for the BF-CCS alternative because the electrolysis technology has a good part load behavior 
and a variable number of stacks can be combined to reach the desired capacity (International Energy Agency (IEA), 2007: 99) (score 3).

Fire and explosion hazard (9.1)

How high is the risk of fire and explosion along the value chain of the alternatives?

The parameter is the risk of fire and explosions according to the security specification sheet of each substance used in each alternative. The standardized security classification is translated into a 5 step scoring system according to (Smola, 2001). The sum across all used substances is then used to rank the four alternatives regarding the fire and explosion hazard (see Table 3-1). The BF-BOF and BF-CCS alternative receive the same safety risk score of 11 (score 1). Most hazardous substances are the natural gas and the carbon monoxide which are easily inflammable. The $\mathrm{CO}_{2}$ sequestration of the BF-CCS route has no impact on the fire hazard. Since hydrogen gas has the same safety score as natural gas and the H-DR alternative does not produce large quantities of carbon monoxide this alternative receives a safety score of 7 (score 3). The EW alternative with a cumulative fire safety score of 3 receives rank 1 (score 4), since it does not have any flammable substances apart from oxygen (see Table 3-1).

\section{Health hazard (9.2)}

How high is the risk of human health damage through the alternatives (apart from fire and explosion?

The parameter assessed is the standardized health hazard according to the security specification sheet of each substance used in each alternative. The standardized security classification is translated into a 5 step scoring system according to (Smola, 2001). The sum across all used substances is then used to rank the four alternatives regarding the health hazard (see Table 3-1). The BF-BOF alternative with a cumulative health risk score of 10 receives rank 3 (score 2). BF$\mathrm{CCS}$ receives the last rank due to the additional potential health hazards of the $\mathrm{CO}_{2}$ transport and underground storage (Metz, 2005: 13), which has not been thoroughly understood (Koornneef et al., 2012: 81). Massive leakage of $\mathrm{CO}_{2}$ gas could have a deadly impact as demonstrated in the lake Nyos catastrophe in 1986 (United Nations Environment Unit, 2005) (score 1). H-DR with the lowest health risk score of 4 receives rank 1 (score 4). EW with a rather 
low overall health risk score of 5 receives rank 2 due to the additional risk of alkali burns of the sodium hydroxide solution (score 3).

\begin{tabular}{|c|c|c|c|c|}
\hline Hazardous substance & $\begin{array}{c}\text { Classification according } \\
\text { to EG } 67 / 548\end{array}$ & $\begin{array}{c}\text { Fire and explosion } \\
\text { hazard }\end{array}$ & Health hazard & Corresponding score \\
\hline \multicolumn{5}{|l|}{ BF-BOF } \\
\hline Natural gas & $\mathrm{R} 12$ & very high & medium & 4 \\
\hline Oxygen & R8 & High & negligible & 3 \\
\hline Carbon Dioxide & N/A & negligible & medium & 0 \\
\hline Carbon Monoxide & $\begin{array}{l}\text { R12; Repr. Cat. 1; R61; R23- } \\
\text { R48 }\end{array}$ & very high & very high & 4 \\
\hline Nitrogen & $\mathrm{N} / \mathrm{A}$ & negligible & medium & 0 \\
\hline Sum & & & & 11 \\
\hline \multicolumn{5}{|l|}{ BF-CCS } \\
\hline Natural gas & $\mathrm{R} 12$ & very high & medium & 4 \\
\hline Oxygen & $\mathrm{R} 8$ & High & negligible & 3 \\
\hline Carbon Dioxide - gaseous & $\mathrm{N} / \mathrm{A}$ & negligible & medium & 0 \\
\hline \begin{tabular}{|l|}
$\begin{array}{l}\text { Carbon Dioxide - dissolved } \\
\text { underground }\end{array}$ \\
\end{tabular} & $\mathrm{N} / \mathrm{A}$ & negligible & high & 0 \\
\hline Carbon Monoxide & $\begin{array}{l}\text { R12; Repr. Cat. 1; R61; R23- } \\
\text { R48 }\end{array}$ & very high & very high & 4 \\
\hline Nitrogen & & negligible & medium & 0 \\
\hline Sum & & & & 11 \\
\hline \multicolumn{5}{|l|}{ H-DR } \\
\hline Hydrogen & $\mathrm{R} 12$ & very high & medium & 4 \\
\hline Oxygen & R8 & High & negligible & 3 \\
\hline Nitrogen & N/A & negligible & medium & 0 \\
\hline \multicolumn{5}{|c|}{ Negligible quantities of carbon dioxide and carbon monoxide from additives in electric arc furnace } \\
\hline Sum & & & & 7 \\
\hline \multicolumn{5}{|l|}{ EW } \\
\hline Sodium Hydroxide & R35 & negligible & high & 0 \\
\hline Oxygen & R8 & High & negligible & 3 \\
\hline Nitrogen & $\mathrm{N} / \mathrm{A}$ & negligible & medium & 0 \\
\hline \multicolumn{5}{|c|}{ Negligible quantities of carbon dioxide and carbon monoxide from additives in electric arc furnace } \\
\hline Sum & & & & 3 \\
\hline
\end{tabular}

Table 3-1: Safety assessment of steelmaking alternatives

\section{Hazard during worst case failure (9.3)}

Which risk exists in a worse case failure for human lives and health? The parameters are severity and probability of the worst case failure. The BF-BOF alternative has a moderate risk of explosion of the blast furnace with severe impact in the proximity (score $\mathbf{3}$ ). The main reasons 
are the intrusion of coolant with an explosive steam creation or carbon dust explosions (Health and Safety Executive, 2001). The BF-CCS alternative has the same risk as the BF-BOF alternative and in addition a risk related to the $\mathrm{CO}_{2}$ transportation and storage, placing this alternative on rank 4 (score 1 ). The H-DR alternative has a moderate probability of an explosion of the direct reduction furnace of the hydrogen storage. The effect would be severe (score 2 ). In the EW alternative the unlikely bursting of the electrolyzer has no severe damage, because no blast wave is generated which makes EW the safest alternative regarding worst case failure (score 4).

\subsubsection{Ecology}

\section{GHG emission (10)}

How high is the specific GHG emission per ton of crude steel with the respective alternative? The assessed parameter is the specific $\mathrm{CO}_{2} \mathrm{e}$ emission simulated for each alternative with the techno-economic model in the moderate scenario in year 2050 (Fischedick et al., 2014). The BFBOF route with $1700 \mathrm{~kg} \mathrm{CO} \mathrm{C}_{2} \mathrm{et} \mathrm{CS}$ has the lowest rank (score 1). The BF-CCS with a reduced emission of $760 \mathrm{~kg} \mathrm{CO}_{2} \mathrm{e} / \mathrm{t} \mathrm{CS}$ receives rank 3 (score 2). The H-DR alternative, with a high share of 'green' electricity, has an emission of only $410 \mathrm{~kg} \mathrm{CO}_{2} \mathrm{e} / \mathrm{t} \mathrm{CS}$ in 2050 and hence receives rank 1 (score 4). EW, which is more dependent on the grid emission factor (EF) emits $560 \mathrm{~kg} \mathrm{CO} 2 \mathrm{e} / \mathrm{t} \mathrm{CS}$ and ranks 2 (score 3).

Since the GHG emission of each alternative depends largely on indirect emission for energy or auxiliary material, there is a strong time dependency of this criterion. BF-BOF shows the highest emission of $\mathrm{CO}_{2}$ e throughout the entire investigation period (score 1). BF-CCS starts out to be the second lowest alternative at market entry in 2020 but with the strong improvements of the carbon free alternatives score only second to last in 2050 (score 3). Due to the ability of H-DR to use a high share of renewable energy (and only small part of grid electricity) this alternative scores high throughout the entire investigation period (score 3 in 2010 and score 4 from then on). EW with a higher share of grid electricity receives score 3 in 2040 and 2050.

\section{Other environmental impacts (11)}

How high is the environmental damage other than through GHG emission?

The parameter representing this criterion is a very broad estimate of the major negative effects each alternative has on the environment apart from GHG emission. 
The BF-BOF alternative emits dust, mainly from the coke oven and the blast furnace that pollutes the air (Remus et al., 2013: 227-307) (score 2). The BF-CCS alternative emits slightly less dust, but involves underground $\mathrm{CO}_{2}$ storage on the other hand that could lead to environmental damage in case of leakage. The uncertainties about long-term effects that carbon underground storage might have still need to be further assessed (score 1) (Metz, 2005: 12-14). The H-DR alternative emits low quantities of dust and waste water from the electric arc furnace. The reducing agent hydrogen is ecologically harmless (score 4). The EW alternative also has little impact on the environment. Apart from low emissions from the electric arc furnace only the sodium hydroxide solution causes water pollution in case of leakage (score 3).

\section{Energy efficiency (12)}

How much final energy is used (including production of reducing agent) for each alternative? The parameter in focus is the final energy demand of each alternative that was simulated with the techno-economic model. The BF-BOF alternative has the highest specific energy demand per ton of CS of $18.1 \mathrm{GJ} / \mathrm{t}$ CS (score 1). This value includes the energy content of the coking coal. The BF-CCS alternative with a reduced demand of coking coal through top gas recycling has a specific energy demand of 15.6 GJ / t CS and ranks third (score 2). The H-DR alternative has the second lowest energy demand of $13.1 \mathrm{GJ} / \mathrm{t}$ CS (score 3). Without any extra transformation step, the electricity based reduction of the EW alternative has the lowest specific energy demand of $9.3 \mathrm{GJ} / \mathrm{t}$ CS (score 4).

An overview of the scoring of all criteria can be found in Appendix Tab-A 1.

\subsection{Weighting}

After having scored all criteria, the next step in an MCA is to summarize the scores for each alternative. Weighting factors are necessary to define the individual weight of each score in the final result, in form of a percentage value. The final result is a weighted average, i.e., the sum of the products of each score with its weighting factor. A neutral, uniformly distributed weighting is used in the first assessment. Each of the five criteria categories receives a weighting of $20 \%$, which is further broken down to the individual criteria and sub-criteria.

Three different sets of weighting factors are selected by the author in order to roughly simulate different stakeholder perspectives from the steel industry, the state government and international 
environmental organisations (see weighting distribution in Figure 4-3). These different sets of weighting factors allow to roughly estimate the effect of different points of view on the four steelmaking alternatives (see section 4.2).

\section{Results}

The final result of the MCA is the weighted average of all criteria for that respective alternative (see Tab-A 1).

For the main assessment the effect of weighting is omitted by equally distributing the weighting factors across all categories and criteria (section Error! Reference source not found.). As additional assessment, the weighting factors are varied to simulate three different perspectives on the alternatives (section 4.2).

\subsection{Scoring}

Applying the scores presented in section 3.1 and distributing the weighting factors equally across all criteria leads to the MCA result for 2050 shown in

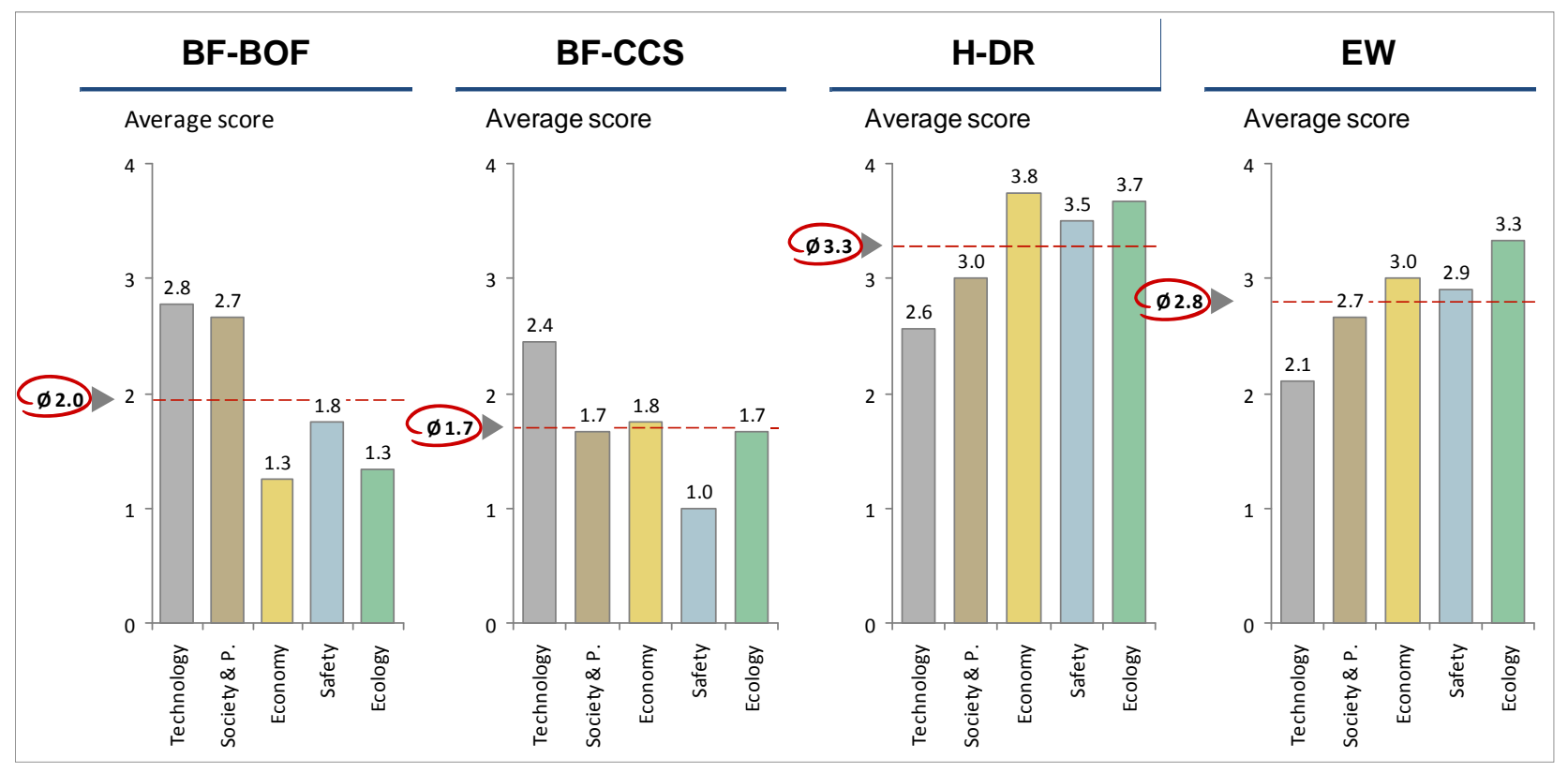

Figure 4-1. 


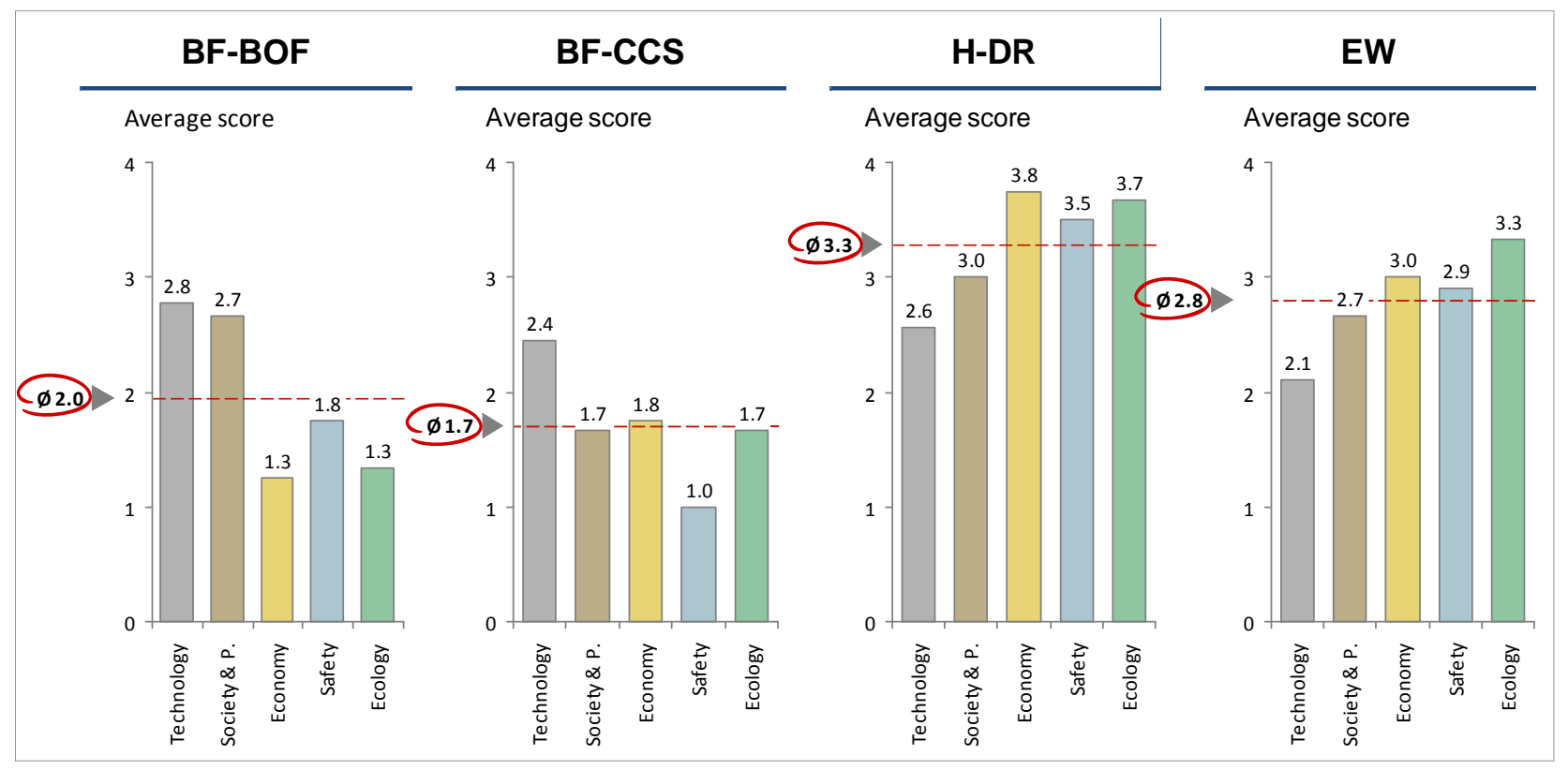

Figure 4-1: Scoring of MCA criteria (with equally distributed weighting)

For each of the four steelmaking routes the average score of each criteria group is displayed together with the overall average score across all criteria groups (red circle), which represents the overall preference for each alternative. Considering the assumed conditions for the year 2050, the time in question, the results for H-DR and EW, the two innovative steelmaking routes, are significantly higher than for the conventional route and the BF-CCS. The preference for the innovative technologies is higher, mainly due to the higher scores in the categories economy, ecology, and safety (which include dependency on raw materials and flexibility in production). $\mathrm{H}$ DR even scores slightly higher than EW in these categories, mainly for two reasons. First, the selective utilisation of peak electricity in combination with hydrogen storage causes a price advantage for H-DR and enables a more flexible production. Secondly, the higher share of grid electricity of $\mathrm{EW}$ results in a higher $\mathrm{CO}_{2} \mathrm{e}$ emission in 2050 when still $20 \%$ of the electricity is generated from fossil sources (see model assumption in Fischedick et al., 2014: 566). EW though has the highest score in innovation potential, which indicates the high future potential of this technology, once marketable.

BF-CCS shows its greatest weakness in the social acceptance and the safety and vulnerability criteria. The conflicting infrastructure investments and the conflicting use of underground storage 
sites in the technology category are compensated by the early marketability and the low intervention intensity of implementation.

BF-BOF has the lowest economy and ecology related score of all assessed routes, which is exactly the main driver for innovative technologies to become competitive. The low economical score is due to the high cost for $\mathrm{CO}_{2} \mathrm{e}$ emission and expected increasing prices for fossil fuels.

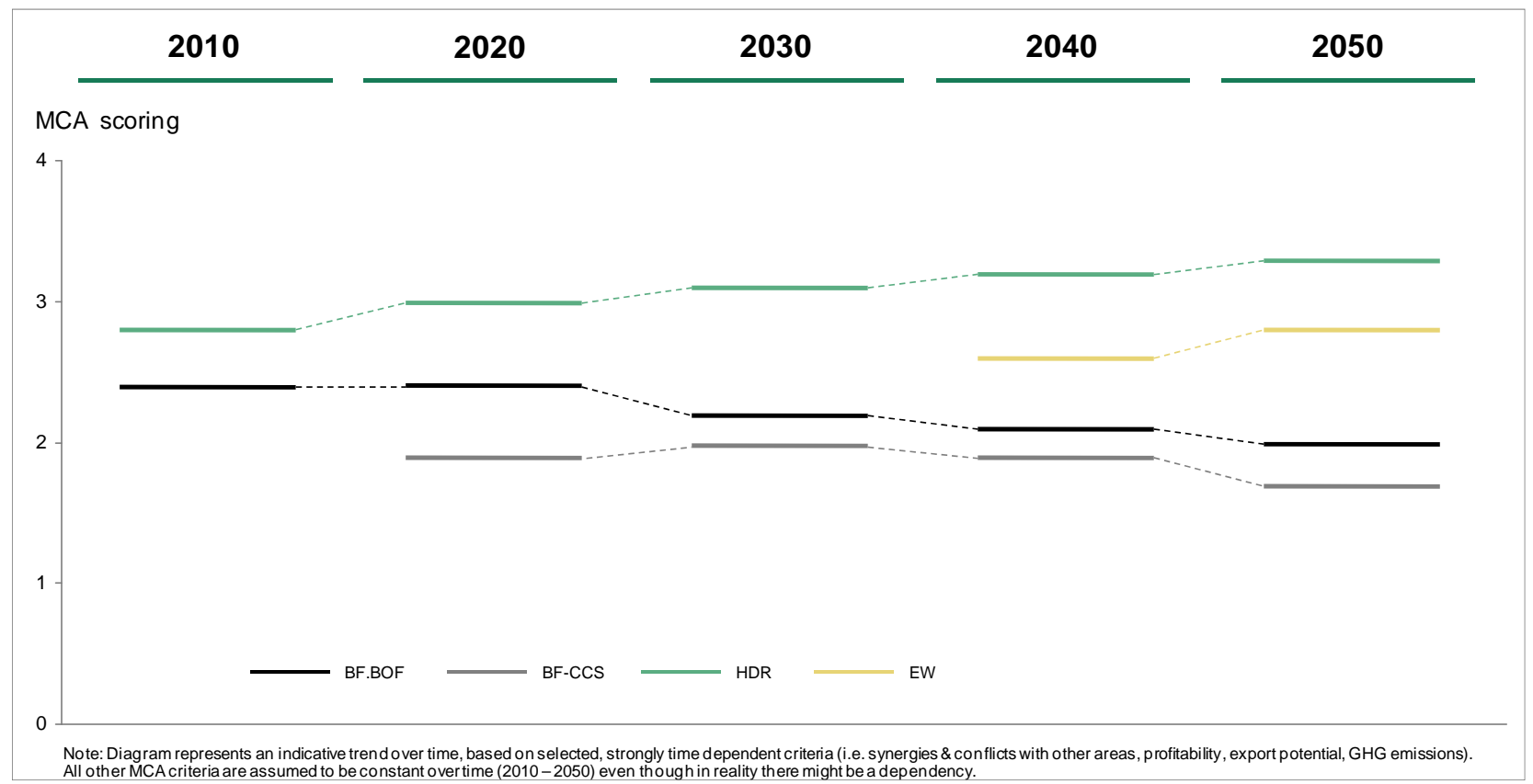

Figure 4-2: Time trend of MCA results

MCA trend over time

As described in section 2.2 the criteria with the strongest time dependency were selected and assessed over time from the base year 2010 until 2050 to gain a first indication of the trend for the overall MCA results. The trend of the total MCA result is shown in Figure 4-2. The shown timely variation depends solely on the variation of the four key time dependent criteria and serves as a rough indication. The actual detailed time development of the MCA would require an MCA model to be developed, which could be an interesting addition in future research but is out of scope for the current paper. If the results from Figure 4-2 are compared to the techno-economic assessment from 2010 - 2050 from part $A$, it is obvious that even though from a commercial perspective H-DR only becomes the most attractive option paste 2040 , considering a wider set of 
criteria leads to H-DR already being the preferred option starting from the base year in 2010 . This is mainly due to a compensation of the economic disadvantages by high scores in the criteria categories society \& politics, safety and ecology. EW instead of being the least profitable alternative when entering the market in 2040, in the MCA trend assessment EW starts out to be the second preferred option in 2040, mainly due to high ecology and safety ratings. BF-CCS which showed the highest profitability in the transition period $(2020-2040)^{6}$ between the conventional steelmaking and the era of the carbon free technologies receives the lowest MCA scores from market entry (2020) until 2050. The profitable business case in this case is counterbalanced by a lack of social acceptance throughout the entire investigation period increasing conflict due to the question on suitable carbon storage sites. Overall the trend assessment shows that the MCA indicates towards the carbon free primary steelmaking technologies much earlier than the pure techno-economical assessment. Intermediated technologies like BF-CCS receive much lower scores if a more holistic assessment is conducted.

\subsection{Exemplary weighting}

Three different sets of weighting factors were chosen by the author to represent different perspectives on the alternatives (see Figure 4-3).

${ }^{6}$ (Fischedick et al., 2014: 571) 


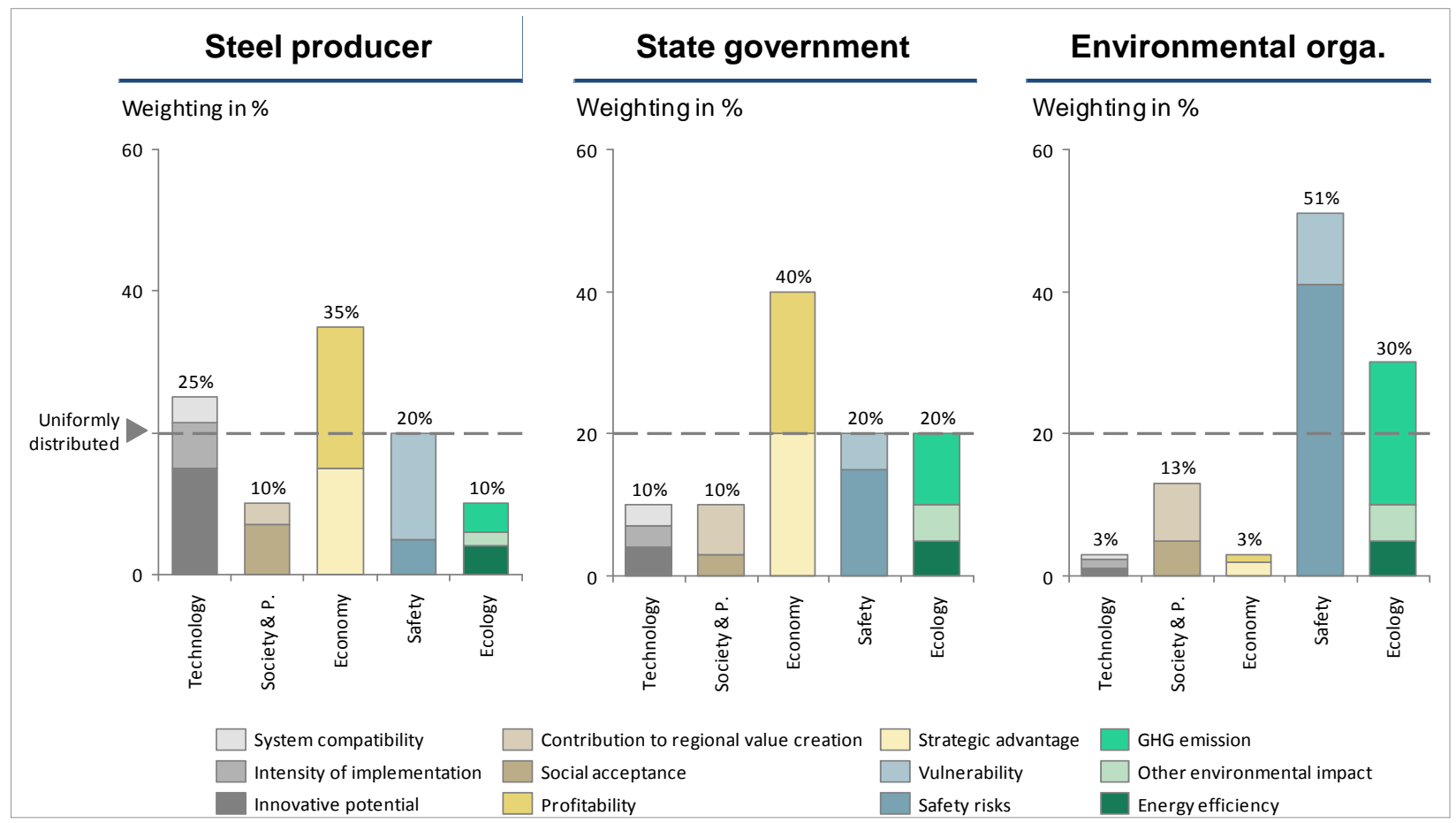

Figure 4-3: Exemplary weighting factors representing different perspectives

The chosen weighting factor distributions result entirely from the author's judgment based on literature information and selective discussions with experts. The steel producer perspective is expected to have the most uniform weighting. The most important categories from this perspective are expected to be the economical and technological categories, which is due the operator point of view with the total cost of ownership in mind.

The government perspective is expected to also weigh the economical aspect very high, because politics are convinced that long lasting prosperity and employment can only be achieved through economical profitability of the industry. Instead of the technological category, the ecological category is expected to be weighted higher, because of the political focus on GHG emission reduction of the involved government.

The environmental organization is expected to have the most accentuated weighting. Apart from rather less weighting in most categories the categories safety and ecology play a significant role. Above $50 \%$ weighting for the safety criteria is due to the expected very high priority for the safety criteria that is usually considered a "show stopper" criterion for the ethics of environmental organisations. If there is a significant safety risk for human life or health, a technology would 
never be acceptable. As an environmental organisation, the weighting for the ecological criteria is also very high, with the emphasis on the related GHG emission of the different technologies. The safety category consists of two distinct aspects: the vulnerability, which contains criteria for the dependency on raw material and production flexibility, and the classical safety risk criteria. The environmental organisation and the government body are both expected to emphasize more on the safety risk. The steel producer perspective though emphasises more on the vulnerability of the technology, which could have detrimental effects for him as operator.

Applying the above-mentioned weighting factors to the criteria scores of section 4.1 leads to three different results of the MCA. In Figure 4-4, the uniformly weighted scores from section 4.1 are compared to the results based on the different sets of weighting factors. Even though the sets of weighting factors are quite different, the final evaluation result for each route is very similar from all three perspectives. The high evaluation results for the innovative routes (H-DR and EW) remain. Through the individual weighting factors they are even accentuated. The reasons for the high evaluation of $\mathrm{H}-\mathrm{DR}$ and $\mathrm{EW}$ differ from the angle of perspective. The steel producer and the government accentuate the economical scores. The environmental organization accentuates the safety and environmental aspects. For the BF-CCS alternative, especially the weighting from the perspective of an environmental organisation, with low weighting of technological and economical aspects, causes this alternative to be the least suitable by far. Even the weighting from the perspective of a steel producer leads to a lower final evaluation of the incumbent BF-BOF alternative compared to a uniformly weighting. Apparently, the preference of the different steelmaking technologies is quite robust even if changing the stakeholder perspective. 


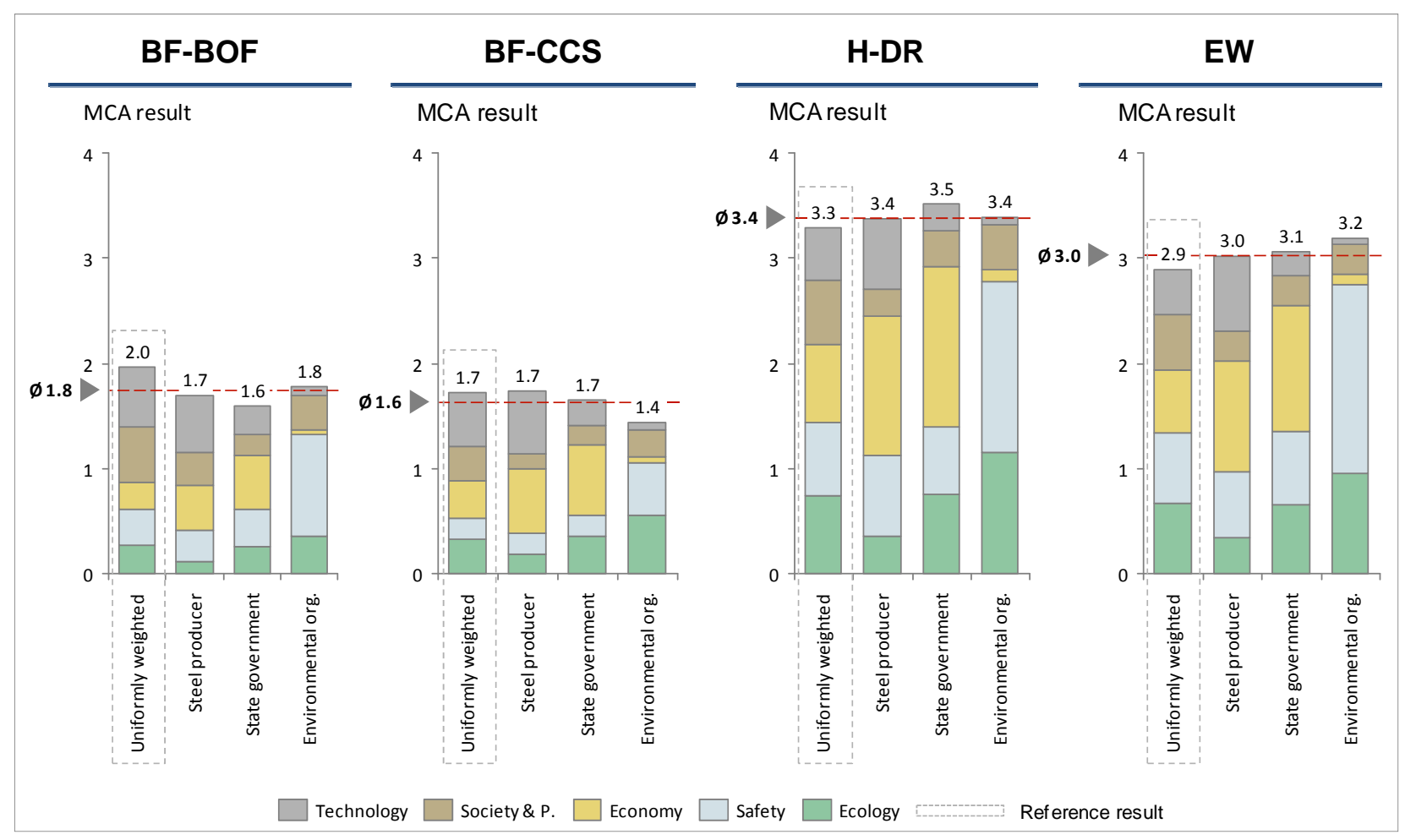

Figure 4-4: Comparison of final MCA results with exemplary weighting factors

\section{Discussion and conclusion}

After having presented the results of the MCA for four possible future steelmaking routes, in the previous section, the conclusions, implications, and limitations are discussed before a brief outlook is given.

\section{Integral evaluation}

In the techno-economic assessment in part A (Fischedick et al., 2014), the hydrogen direct reduction $(\mathrm{H}-\mathrm{DR})$ and electrowinning $(\mathrm{EW})$ routes where assessed to be future primary steelmaking technologies that could enable economically viable emission reduction in line with an ambitious 2050 GHG reduction target in Germany (BMU, 2010). Nevertheless, it was concluded that a broader assessment would be necessary to gain a more holistic understanding of future 
steelmaking routes in Germany. Hence, a MCA with 20 different criteria and sub-criteria from 5 categories was conducted in the present paper.

The results of the MCA for the assessed steelmaking routes in Germany are much in line with the prior assessment. The innovative technologies $\mathrm{H}-\mathrm{DR}$ and EW receive a significantly higher score then the integrated route (BF-BOF) and the integrated route with CCS (BF-CCS). Not only economical and technical aspects, but especially environmental, safety and vulnerability aspects lead to a preference for the H-DR. Only the society \& politics criteria category, which includes criteria such as regional value creation and social acceptance, results in higher evaluation results for the BF-BOF route. A major technology break bears the risk of affecting the entire supply chain, threatening local employment, industry structure and depending on specific conditions social acceptance. The economical and ecological advantage of H-DR compensates these risks and results in an overall higher scoring. Main advantage of H-DR over EW is the decoupling of the electricity demand from the continuous operation through the possibility of hydrogen storage. Renewable peak electricity can be consumed selectively, leading to a price and environmental advantage under specific market conditions. Additional revenues through hydrogen storage and synergies with other sectors (like transport, other industry related applications) are further factors to be considered. Overall, H-DR shows the highest suitability across all criteria to become the primary steelmaking route of the future in the German market.

A first trend analysis reveals that according to the MCA results H-DR already received the highest scores in the base year, strengthening its advantage over the other alternatives until 2050. BF-CCS on the other hand stays with the lowest MCA scores from 2020 until 2050 without passing BF-BOF as the preferred intermediate option, as seen in the techno-economic model in part A.

\section{Different perspectives}

Even though the weighting factors used to simulate different stakeholder perspectives show distinct distributions, the effect on the final MCA result is rather small. This leads to the conclusion that the assessment of $\mathrm{H}$-DR as the preferred steelmaking route, amongst the four routes examined, is rather robust. The evaluation results based on different weighting factors all lie within a $20 \%$ range of the uniformly weighted reference results. This similarity could indicate a 
potential consensus across stakeholder groups on the future of the Germany steel industry which would facilitate to solve remaining future challenges.

The only significant deviation from the homogenous evaluation was found for the perspective of an environmental organisation. With a very high weight for the safety criteria, BF-CCS is scored about 20\% lower, EW about 10\% higher. From the perspective of a steel producer and the government BF-BOF and BF-CCS are both evaluated very similar. Considering the perspective of an environmental organisation, the BF-BOF appears to be more suitable, mainly because BFCCS lacks the social acceptance. From the steel producer perspective, the innovative potential of the EW route is the highest of all, indicating the future potential this technology might bear if marketability is reached.

However, the integral evaluation of the four primary steelmaking technologies underlines the suitability of the H-DR route as future technology. The EW route with slight economical disadvantages is considered to have a high innovative potential that might enable this route to become equally suitable towards the end of the investigation period, if technical maturity is reached.

\section{Implications}

Similar to the implications of (Fischedick et al., 2014) the current research underlines the importance of the H-DR and EW routes for the future of the German steel industry. With this research results, decision makers from politics and industry are provided with guidance on which technological option to bring forward. Specific innovation programs are necessary to minimize the time to market of the preferred option and to avoid a lock-in on the incumbent technologies that clearly show a low viability in long-term future. With long investment cycles in the steel industry, stringent strategies have to be put into place as soon as possible. Consequent political guidance is necessary and will direct the transformation most effectively towards the desired future state.

The robustness of the MCA results from different perspective indicates a great opportunity to reach a political consensus across stakeholder groups and to work towards a common future state. Since H-DR and EW both receive very high results, both options should be further pursued. Primarily, the compatibility with the changing energy landscape and synergies with other sectors will define which option is more suitable. 
However, even if both innovative steelmaking routes seem to be promising future options, the question of preference always depends on the specific site conditions. For a specific steel company with its unique technical, economic and social environment there might be reasons to select other steelmaking routes.

\section{Limitations}

Selecting a set of criteria for the MCA has to be done with great care. No major aspect should be neglected. The criteria should be mutually exclusive and collectively exhaustive. Nevertheless, some dependency between the criteria still exists and leads to a more or less severe double counting of certain aspects (e.g., criteria like employment, GHG emission, and energy efficiency also affect the criteria profitability indirectly).

The holistic characteristic of a MCA comes with the disadvantage to have many qualitative, hard to score criteria. The scoring is conducted in a quantitative manner whenever possible. Literature references are used for the scoring wherever existing. For some criteria (e.g. profitability, GHG emission) simulation results from the techno-economic model from (Fischedick et al., 2014) were used. These qualitative simulations bear a lot of uncertainties, as the model assumption vary over the investigation period and could be influenced by many external effects (see Fischedick et al., 2014: 577-578). Especially the scoring of the rather qualitative criteria bears the risk of being influenced by subjective misjudgement of the author. In a MCA, universally acceptable (objective) solutions are no longer feasible (Zopounidis and Pardalos, 2010: 6).

In the present research the focus lies on the scoring of the steelmaking technologies and the different weighting factors are only intended to assess the robustness of the MCA result. In future research a statistically representative determination of weighting factors from different stakeholder groups could be an interesting addition to assess the real potential for a consensus. The current research only evaluates primary steelmaking options in the German market. Even though model inputs and certain MCA criteria consider developments on the international steel market, further assessments at different locations would lead to a more international understanding of the steelmaking future.

The four exemplary primary steelmaking routes discussed in Germany are only a small portion of the spectrum of possible GHG mitigation measures with regard to the steel industry. A combination of different process steps and aggregates and mixing of raw materials and intermediate products could lead to many other viable future steelmaking options, suitable for specific production sites in specific market environments, which could be assessed in future 
research. Achievements in other areas like scrap recycling, steel demand reduction, or production efficiency increase have direct impact on the requirements of the primary steelmaking. In order to achieve the 2050 reduction targets a combination of different measures will be necessary (Milford et al., 2013).

\section{Outlook}

After a holistic assessment of four steelmaking technologies, on the practical side the current findings should be implemented in strategies and roadmaps. The potential for a consensus across different stakeholder groups should be realised by intensive dialogue processes. On the research and development side, scientific insights have to be put into practice as fast as possible through close cooperation of research and industry (e.g., technology innovation think tanks and innovation cluster). 


\section{Appendix}

Tab-A 1: Scoring and weighting of MCA criteria

\begin{tabular}{|c|c|c|c|c|c|c|c|c|c|}
\hline \multirow[b]{2}{*}{ Category } & \multirow[b]{2}{*}{ Criteria / Sub-criteria } & \multicolumn{4}{|c|}{ Corresponding score } & \multicolumn{4}{|c|}{ Weighting } \\
\hline & & $\begin{array}{l}\text { BF- } \\
\text { BOF }\end{array}$ & $\begin{array}{l}\text { BF- } \\
\text { CCS }\end{array}$ & H-DR : & EW & Even & $\begin{array}{c}\text { Steel- } \\
\text { producer }\end{array}$ & Politics & $\begin{array}{c}\text { Environ- } \\
\text { ment }\end{array}$ \\
\hline \multicolumn{2}{|l|}{ Technology } & 2,8 & 2,4 & 2,6 & 2,1 & $20 \%$ & $25 \%$ & $10 \%$ & $3 \%$ \\
\hline 1 & System compatibility & 3,3 & 2,3 & 2,7 & 1,3 & $5,0 \%$ & $3,5 \%$ & $3,0 \%$ & $0,8 \%$ \\
\hline 1.1 & Technological marketability & 4 & 2 & 3 & 1 & $1,7 \%$ & $1,5 \%$ & $1,0 \%$ & $0,3 \%$ \\
\hline 1.2 & Availability reducing agent & 3 & 4 & 1 & 2 & $1,7 \%$ & $1,5 \%$ & $1,0 \%$ & $0,3 \%$ \\
\hline 1.3 & Synergies / conflict with other areas & 3 & 1 & 4 & 1 & $1,7 \%$ & $0,5 \%$ & $1,0 \%$ & $0,3 \%$ \\
\hline 2 & Intensity of intervention & 4 & 3 & 2 & 1 & $8,4 \%$ & $6,5 \%$ & $3,0 \%$ & $1,3 \%$ \\
\hline 3 & Innovative potential & 1 & 2 & 3 & 4 & $6,7 \%$ & $15,0 \%$ & $4,0 \%$ & $1,0 \%$ \\
\hline \multicolumn{2}{|c|}{ Society \& Politics } & 2,7 & 1,7 & 3,0 & 2,7 & $20,0 \%$ & $10,0 \%$ & $10,0 \%$ & $13,0 \%$ \\
\hline 4 & Contribution to regional value creation & 1,3 & 2,3 & 4,0 & 2,3 & $10,0 \%$ & $3,0 \%$ & $7,0 \%$ & $8,0 \%$ \\
\hline 4.1 & Effect on local employment & 1 & 2 & 4 & 3 & $3,3 \%$ & $1,0 \%$ & $2,0 \%$ & $3,0 \%$ \\
\hline 4.2 & New regional value creation & 2 & 3 & 4 & 1 & $3,3 \%$ & $1,0 \%$ & $1,0 \%$ & $5,0 \%$ \\
\hline 4.3 & Potential to conserve industry structure & 1 & 2 & 4 & 3 & $3,3 \%$ & $1,0 \%$ & $4,0 \%$ & $0,0 \%$ \\
\hline 5 & Social acceptance & 4 & 1 & 2 & 3 & $10,0 \%$ & $7,0 \%$ & $3,0 \%$ & $5,0 \%$ \\
\hline \multicolumn{2}{|l|}{ Economy } & 1,3 & 1,8 & 3,8 & 3,0 & $20,0 \%$ & $35,0 \%$ & $40,0 \%$ & $3,0 \%$ \\
\hline 6 & Profitability & 1 & 2 & 4 & 3 & $10,0 \%$ & $20,0 \%$ & $20,0 \%$ & $1,0 \%$ \\
\hline 7 & Strategic advantage & 2 & 2 & 4 & 3 & $10,0 \%$ & $15,0 \%$ & $20,0 \%$ & $2,0 \%$ \\
\hline 7.1 & Advantage through pioneer strategy & 2 & 1 & 4 & 3 & $5,0 \%$ & $8,0 \%$ & $12,0 \%$ & $1,0 \%$ \\
\hline 7.2 & Export potential & 1 & 2 & 3 & 3 & $5,0 \%$ & $7,0 \%$ & $8,0 \%$ & $1,0 \%$ \\
\hline \multicolumn{2}{|c|}{ Safety \& Vulnerability } & 1,8 & 1,0 & 3,5 & 2,9 & $20,0 \%$ & $20,0 \%$ & $20,0 \%$ & $51,0 \%$ \\
\hline \multicolumn{2}{|r|}{ Vulnerability } & 1,5 & 1,0 & 4,0 & 3,0 & $10,0 \%$ & $15,0 \%$ & $5,0 \%$ & $10,0 \%$ \\
\hline 8.1 & Raw material dependency & 1 & 1 & 4 & 3 & $5,0 \%$ & $10,0 \%$ & $4,0 \%$ & $5,0 \%$ \\
\hline 8.2 & Flexibility of production & 2 & 1 & 4 & 3 & $5,0 \%$ & $5,0 \%$ & $1,0 \%$ & $5,0 \%$ \\
\hline 9 & Safety risks & 2,0 & 1,0 & 3,0 & 3,7 & $10,0 \%$ & $5,0 \%$ & $15,0 \%$ & $41,0 \%$ \\
\hline 9.1 & Fire and explosion hazard & 1 & 1 & 3 & 4 & $3,3 \%$ & $2,0 \%$ & $5,0 \%$ & $13,7 \%$ \\
\hline 9.2 & Health hazard & 2 & 1 & 4 & 3 & $3,3 \%$ & $2,0 \%$ & $5,0 \%$ & $13,7 \%$ \\
\hline 9.3 & Hazard during failure & 3 & 1 & 2 & 4 & $3,3 \%$ & $1,0 \%$ & $5,0 \%$ & $13,7 \%$ \\
\hline \multicolumn{2}{|l|}{ Ecology } & 1,3 & 1,7 & 3,7 & 3,3 & $20,0 \%$ & $10,0 \%$ & $20,0 \%$ & $30,0 \%$ \\
\hline 10 & GHG emission & 1 & 2 & 4 & 3 & $6,7 \%$ & $4,0 \%$ & $10,0 \%$ & $20,0 \%$ \\
\hline 11 & Other environmental impact & 2 & 1 & 4 & 3 & $6,7 \%$ & $2,0 \%$ & $5,0 \%$ & $5,0 \%$ \\
\hline 12 & Energy efficiency & 1 & 2 & 3 & 4 & $6,7 \%$ & $4,0 \%$ & $5,0 \%$ & $5,0 \%$ \\
\hline \multicolumn{2}{|c|}{ Weighted average } & 2,0 & 1,7 & 3,3 & $\overline{2,8}$ & $100 \%$ & $100 \%$ & $100 \%$ & $100 \%$ \\
\hline
\end{tabular}

Tab-A2: Time trend of selected criteria

\begin{tabular}{|c|c|c|c|c|c|c|c|c|c|c|c|c|c|c|c|c|c|c|c|c|c|}
\hline Category & Criteria / Sub-criteria & $\begin{array}{l}\text { BF- } \\
\text { BOF }\end{array}$ & 2 & $\begin{array}{l}10 \\
\mathrm{H}- \\
\text { DR } \\
\end{array}$ & EW & BF- & $\begin{array}{r}20 \\
\text { BF- } \\
\text { CCS } \\
\end{array}$ & $\begin{array}{l}20 \\
\mathrm{H}- \\
\mathrm{DR}\end{array}$ & EW & $\begin{array}{l}\mathrm{BF}- \\
\mathrm{BOF}\end{array}$ & $\begin{array}{l}20 \\
\text { BF- } \\
\text { CCS }\end{array}$ & $\begin{array}{l}030 \\
\mathrm{H}- \\
\mathrm{DR}\end{array}$ & $\mathrm{EW}$ & $\mathrm{BF}-$ & $\begin{array}{l}20 \\
\text { BF- } \\
\text { CCS }\end{array}$ & $\begin{array}{l}40 \\
\mathrm{H}- \\
\mathrm{DR}\end{array}$ & EW & BF- & $\begin{array}{l}20 \\
\mathrm{BF}- \\
\mathrm{CCS} \\
\end{array}$ & $\begin{array}{l}050 \\
\mathrm{H}- \\
\mathrm{DR}\end{array}$ & $\mathrm{EW}$ \\
\hline 1.3 & $\begin{array}{l}\text { Synergies / conflict } \\
\text { with other areas }\end{array}$ & 4 & 1 & 1 & 1 & 4 & 1 & 1 & 1 & 4 & 1 & 3 & 1 & 3 & 1 & 3 & 1 & 3 & 1 & 4 & 1 \\
\hline 6 & Profitability & 4 & 3 & 1 & 2 & 4 & 3 & 2 & 1 & 3 & 4 & 2 & 1 & 2 & 4 & 3 & 1 & 1 & 2 & 4 & 3 \\
\hline 7.2 & Export potential & 4 & 3 & 1 & 1 & 4 & 3 & 2 & 1 & 1 & 3 & 3 & 2 & 1 & 2 & 3 & 3 & 1 & 2 & 3 & 3 \\
\hline 10 & GHG emission & 1 & 4 & 3 & 2 & 1 & 3 & 4 & 2 & 1 & 3 & 4 & 2 & 1 & 3 & 4 & 2 & 1 & 2 & 4 & 3 \\
\hline
\end{tabular}




\section{References}

Abu Taha, R., Daim, T., 2013. Multi-Criteria Applications in Renewable Energy Analysis, a Literature Review, in: Daim, T., Oliver, T., Kim, J. (Eds.), Research and Technology Management in the Electricity Industry. Springer London, London, pp. 17-30.

Balat, M., 2008. Potential importance of hydrogen as a future solution to environmental and transportation problems. International Journal of Hydrogen Energy 33, 4013-4029.

Birol, F., Cozzi, L., Gül, T., 2013. World Energy Outlook Special Report. Redrawing The EnergyClimate Map, Paris.

BMU, 2010. Energiekonzept für eine umweltschonende, zuverlässige und bezahlbare Energieversorgung. http://www.bundesregierung.de/Content/DE/_Anlagen/2012/02/energiekonzeptfinal.pdf? _blob=publicationFile\&v=5.

Department of Communities and Local Governement, 2009. Multi-criteria analysis: a manual, London.

ECORYS SCS Group, 2008. Study on the Competitiveness of the European Steel Sector. Within the Framework Contract of Sectoral Competitiveness Studies - ENTR/06/054, Rotterdam.

EUROFER, 2013. A Steel Roadmap for a Low Carbon Europe 2050, Brüssel.

European Commission, 2011. A Roadmap for moving to a competitive low carbon economy in 2050. Communication from the Commission to the European Parliament, the Council, the European Econmic and Social Committee and the Committee of the regions, Brussel.

Expert from steel industry, 2014. Interview about technical specifications of innovative steelmaking technologies.

Fischedick, M., Marzinkowski, J., Winzer, P., Weigel, M., 2014. Techno-economic evaluation of innovative steel production technologies. Journal of Cleaner Production 84, 563-580.

Franco, A., Montibeller, G., 2009. Problem Structuring for Multi-Criteria Decision Analysis Interventions, London.

Health and Safety Executive, 2001. The explosion of No. 5 Blast Furnace, Corus UK Ltd, Port Talbot. Health and Safety Executive 09/08.

Intergovernmental Panel for Climate Change (IPCC), 2014. Climate Change 2014. Working Group III Contribution to the IPCC Fifth Assessment Report (AR5), Cambridge.

International Energy Agency (IEA), 2007. IEA Agreement on the Production and Utilization of Hydrogen. Task 18 Subtask B Final Report: Hydrogen Demonstration Project Evaluations.

International Organization for Standardization (ISO), 2013. Environmental management Environmental performance evaluation - Guidelines (14031).

Kirschen, M., Badr, K., Pfeifer, H., 2011. Influence of direct reduced iron on the energy balance of the electric arc furnace in steel industry. Energy 36, 6146-6155.

Koornneef, J., Ramírez, A., Turkenburg, W., Faaij, A., 2012. The environmental impact and risk assessment of $\mathrm{CO} 2$ capture, transport and storage - An evaluation of the knowledge base. Progress in Energy and Combustion Science 38, 62-86.

Lavelaine, H., Allanore, A., 2008. Optimized Design of an Iron Electrowinning Cell, Maizières-lèsMetz.

Mateo, José Ramón San Cristóbal, 2012. Multi criteria analysis in the renewable energy industry. Springer, London, New York.

Metz, B., 2005. IPCC special report on carbon dioxide capture and storage, Cambridge. 
Milford, R.L., Pauliuk, S., Allwood, J.M., Müller, D.B., 2013. The Roles of Energy and Material Efficiency in Meeting Steel Industry CO 2 Targets. Environ. Sci. Technol. 47, 3455-3462.

Morfeldt, J., Nijs, W., Silveira, S., 2014. The impact of climate targets on future steel production an analysis based on a global energy system model. Journal of Cleaner Production.

Nuber, D., Eichberger, H., Rollinger, B., 2006. Circored fine ore direct reduction. Millenium Steel 2006, 37-40.

Oei, P.-Y., Herold, J., Tissen, A., 2011. $\mathrm{CO}_{2}$ Speicherung in Deutschland: Eine Brückentechnologie als Klimalösung? Z Energiewirtsch 35, 263-273.

Pauliuk, S., Milford, R.L., Müller, D.B., Allwood, J.M., 2013. The Steel Scrap Age. Environ. Sci. Technol., 130307142353004.

Ranzani da Costa, A., Wagner, D., Patisson, F., 2013. Modelling a new, low CO2 emissions, hydrogen steelmaking process. Journal of Cleaner Production 46, 27-35.

Remus, R., Roudier, S., Aguado-Monsonet, M., Aguado-Monsonet, M.A., Delgado Sancho, L., 2013. Best Available Techniques (BAT) Reference Document for Iron and Steel Production // Best available techniques (BAT) reference document for iron and steel production. Industrial Emissions Directive 2010/75/EU (Integrated Pollution Prevention and Control) // Industrial emissions directive 2010/75/EU: integrated pollution prevention and control, Luxemburg. http://www.worldcat.org/oclc/847463021.

Smola, T., 2001. Das Spaltenmodell. Eine Hilfestellung zur Gefahrenermittlung und Ersatzstoffprüfung nach $\S 16$ Gefahrstoffverordnung, Sankt Augustin.

United Nations Environment Unit, 2005. Lake Nyos Dam Assessment, Geneva, Switzerland.

Wang, J.-J., Jing, Y.-Y., Zhang, C.-F., Zhao, J.-H., 2009. Review on multi-criteria decision analysis aid in sustainable energy decision-making. RENEWABLE \& SUSTAINABLE ENERGY REVIEWS 13, 2263-2278.

World Meteorological Organization, 2013. WMO Greenhouse Gas Bulletin.

World Steel Association, 2014. World Steel in Figures 2014, Brüssel. http://www.worldsteel.org/media-centre/press-releases/2014/World-Steel-in-Figures-2014-isavailable-online.html. Accessed June 30, 2014.

Wörtler, M., Schuler, F., Voigt, N., Schmidt, T., Dahlmann, P., Lüngen, H.B., Ghenda, J.-T., 2013. Steel's contribution to a low carbon Europe 2050. Technical and economic analysis of the sectors $\mathrm{CO}_{2}$ abatement potential, Boston.

Wuppertal Institute for Climate, Environment, and Energy (WI) (Ed.), 2012. Sustainable use of excess wind power shares. A multi criteria analysis of different grid- and storage options.

Yetano Roche, M., Mourato, S., Fischedick, M., Pietzner, K., Viebahn, P., 2010. Public attitudes towards and demand for hydrogen and fuel cell vehicles: A review of the evidence and methodological implications. Energy Policy 38, 5301-5310.

Yuan, B., Haarberg, G.M., 2008. Electrowinning of Iron in Aqueous Alkaline Solution Using Rotating Disk Electrode, Trondheim.

Zeiss, C., Valentin, D., 2011. Klimaschutz NRW 2020+ (2050). Handlungsoptionen und Handlungsnotwendigkeiten. Im Auftrag des Ministerium für Klimaschutz, Umwelt, Landwirtschaft, Natur und Verbraucherschutz (MKULNV) des Landes Nordrhein-Westfalen, Wuppertal.

Zopounidis, C., Pardalos, P.M., 2010. Handbook of Multicriteria Analysis. Springer Berlin Heidelberg, Berlin, Heidelberg. 